\title{
Students' Perceptions about Social Constructivist Learning Environment in e-learning
}

\author{
Fahmeeda Adib Azhari', Nurul Nashuha Jasmi ${ }^{1}$, Mohd Shahezwan Abd Wahab ${ }^{1, \star}$, Suhaidah Mohd \\ Jofrry ${ }^{1}$, Kah Seng Lee ${ }^{2}$, Long Chiau Ming ${ }^{3,4, *}$
}

${ }^{1}$ Faculty of Pharmacy, Universiti Teknologi MARA (UiTM) Cawangan Selangor, Kampus Puncak Alam, Bandar Puncak Alam, Selangor, MALAYSIA.

${ }^{2}$ Faculty of Pharmacy, Cyberjaya University College of Medical Sciences (CUCMS), Cyberjaya, Selangor, MALAYSIA.

${ }^{3}$ Pharmacy, School of Medicine, College of Health and Medicine, University of Tasmania, Hobart, AUSTRALIA.

${ }^{4}$ PAPRSB Institute of Health Sciences, Universiti Brunei Darussalam, Bandar Seri Begawan, Brunei Darussalam, BRUNEI.

\begin{abstract}
Aim/Background: Pharmacy educators often incorporate electronic learning or e-learning to facilitate learning among pharmacy students. E-learning can be designed based on the Social Constructivism Theory (SCT). The learning outcomes of e-learning that is developed based on the SCT should be assessed continuously and they should include the evaluation of students' perceptions on the Social Constructivist Learning Environment (SCLE) of their e-learning. The present study aims to investigate pharmacy students' expectations for their e-learning and evaluate the extent to which e-learning fulfils their expectations. Methods: A cross-sectional survey was carried out among the second- and third-year undergraduate pharmacy students in a Malaysian Public University to assess the students' perceptions on the SCLE of two e-learning components offered in two core courses: Principle of Pathology (PP) and Pharmaceutical Care (PC) using the Constructivist Online Learning Environment Survey (COLLES). Results: All students who were invited to participate in the study responded to the survey (response rate $=100 \%, n=336$ ). In general, students had positive but moderate expectations and satisfaction towards e-learning. Students mostly expected e-learning to be relevant to their professional practice. The second-year PP students were satisfied with their e-learning, but the third year PC students rated their experience to be lower than their expectations. Conclusion: As a conclusion, although e-learning that was developed based on the SCT can resulted in SCLE, the expectations of the third-year pharmacy students were harder to fulfil compared to their younger counterparts. This warrants innovation in e-learning content and processes for the third-year students.
\end{abstract}

Key words: Constructivist Online Learning Environment Survey, e-learning, Pathology, Pharmaceutical Care, Social Constructivist Learning Environment.

\section{INTRODUCTION}

Electronic learning or e-learning has become common in pharmacy education. E-learning is defined as learning conducted through the Internet ${ }^{1}$ and has been used to facilitate learning in various topics in pharmacy education. ${ }^{2-4}$ E-learning can be offered to students to complement the traditional teaching method in a blended learning environment. ${ }^{5}$ E-learning is relevant in pharmacy education in many ways. E-learning is flexible so that teaching materials can be accessed at times and places convenient to the students. In addition, due to its flexibility, e-learning allows students to consolidate their understanding on various topics at their own pace, thereby allowing slow learners to catch up, without holding back fast learners. Since students can revisit e-learning materials, e-learning provides more control for the students compared to learning through conventional methods. The flexibility of e-learning also provides a means to introduce pharmacy topics or teaching materials in the usually crowded pharmacy curricula. ${ }^{6}$
Submission Date: 22-10-2019; Revision Date: 31-12-2019; Accepted Date: 14-02-2020

DOI: 10.5530/ijper.54.2.31 Correspondence:

Dr. Mohd Shahezwan Abd Wahab

Faculty of Pharmacy,

Universiti Teknologi MARA (UiTM) Cawangan Selangor, Kampus Puncak Alam, 42300, Puncak Alam, Selangor, MALAYSIA. Phone: +603-32584620 E-mail: ewan.pharmcare@ gmail.com

Assoc. Prof. Dr. Long Chiau Ming

PAPRSB Institute of Health Sciences, Universiti Brunei Darussalam, Jalan Tungku Link, Gadong BE1410,

Brunei Darussalam, BRUNEI.

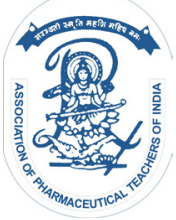

www.ijper.org 
Furthermore, since future pharmacists are expected to engage in independent lifelong self-directed learning throughout their careers, incorporating e-learning in pharmacy education provides them with the skills and readiness to utilize this form of learning. ${ }^{7}$ Moreover, the contemporary pharmacy students have grown up with interactive technologies (e.g., computers, smart phones, video games, etc.) and thus are used to using the Internet in their daily lives. ${ }^{8}$ Additionally, pharmacy students have been shown to be comfortable using the Internet as a source of information. ${ }^{9}$ The high accessibility of the Internet in the present time,${ }^{10}$ coupled with students' acceptance for interactive technologies, makes e-learning a highly viable teaching method in pharmacy education. ${ }^{8}$ E-learning provides the opportunity for pharmacy educators to connect with students through a platform that they prefer. ${ }^{8}$

Previous studies have shown that e-learning is generally accepted, $, 11,12$ increased knowledge, ${ }^{2,11,13}$ improved confidence, ${ }^{11,12,14}$ and promoted interests among students in various pharmacy-related topics. ${ }^{13}$ Studies have also shown that e-learning is comparable to the traditional teaching method in changing learners' knowledge. Moreover, the knowledge gained from e-learning has been noted to be better compared to having no training. ${ }^{2-4}$ Nevertheless, an effective e-learning requires thorough planning and proper selection of materials. Materials that are selected in e-learning should be relevant, up-todate and sufficiently interesting to motivate students to engage in learning activities. In addition, tutors should have a strong commitment to maintain and facilitate learning processes. Therefore, it is ideal for e-learning components in pharmacy education to be developed based on the social constructivist principles. ${ }^{15}$

According to the Social Constructivism Theory (SCT), knowledge construction is both a cognitive and social process. Based on the SCT, students construe and construct meanings by actively collaborating with others by sharing and receiving information. Therefore, to achieve Social Constructivist Learning Environment (SCLE), an interactive process should occur among students and both their peers and tutors by discussing, negotiating and sharing information. ${ }^{16}$ Important for the pharmacy educators and e-learning developers, students' perceptions of their preferred online classroom environment and their actual experience should be assessed. ${ }^{17}$ This can help tutors to continuously reshape e-learning materials and tailor the components to meet students' needs. The primary aims of the present study are to investigate pharmacy students' expectations for online learning environment and to evaluate the extent to which e-learning components in our teachings that are built based on SCT fulfil their expectations.

\section{MATERIALS AND METHODS \\ Design and study participants}

A cross-sectional survey was carried out among the second- and third-year students of the Faculty of Pharmacy, Universiti Teknologi MARA (UiTM), Malaysia to investigate their perceptions about SCLE of two e-learning components offered in two core courses: Principle of Pathology (PP) and Pharmaceutical Care (PC). In UiTM, all second- and third-year students enrol in the PP and PC courses, respectively. Both the PP and PC courses are a 3-credit unit compulsory course, that run over 14 weeks and incorporate both face-to-face lectures and e-learning. The incorporation of both traditional classroom and online learning in teachings is a common practice in UiTM. ${ }^{18}$

Students who attended the two courses were chosen as the study population since the e-learning components of the two courses were developed based on the SCT. Furthermore, these two courses are offered and managed by the same team of tutors. Although the aims and contents of each course are different, both courses utilized the same platform and approaches for e-learning. In addition, the inclusion of the two courses that vary in terms of complexity and required level of thinking skills may provide insights on how these differences influence students' perceptions about SCLE. The present study received approval from the ethics committee of UiTM (600-FF.PT.9/19).

\section{i-Learn system}

For both courses, the e-learning components were developed, uploaded and monitored by course tutors to ensure that the contents are relevant, up-to-date and interesting. The delivery of the e-learning materials utilizes "i-Learn", an online learning management system developed by the academic affairs division of UiTM. This online learning management system aims to stimulate, deliver, guide and manage learning processes among students. ${ }^{19}$ Using this system, tutors are able to upload teaching materials (e.g., course information, lecture slides, audio files, videos, etc.) and administer online quizzes. The system also supports virtual discussion among students through the "i-Discuss" feature of the system. Through this feature, tutors post interesting questions or clinical cases to stimulate discussions among students. The discussions are facilitated and monitored by tutors. Through the online discussions, students share their ideas and opinions, suggest 
solutions, ask questions and present argument. In addition, students are able to use the i-Learn system to consult tutors or clarify any issues privately. All students in UiTM receive training to use the i-Learn system in their first semester. Additionally, they may consult a faculty member who has been appointed as the system consultant to receive advice in regard to technical matters. The i-Learn system provides freedom for the students in terms of time and convenience as it can be accessed anytime and anywhere. It also allows the students to revisit all teaching materials that have been uploaded in the system.

\section{Study instrument}

In the present study, SCLE was assessed using the Constructivist Online Learning Environment Survey (COLLES) that was developed by Taylor and Maor. ${ }^{17}$ The COLLES contains six scales with each scale being represented by four items, resulting in 24 items for the whole survey instrument. The six scales reflect the social constructivist principles, making it suitable to be used for assessment of teachings that are based on SCT. The SCLE aspects that are assessed by the COLLES include (i) relevance: the extent to which the students think e-learning is relevant to their professional practices (4 items); (ii) reflection: the extent to which e-learning promotes students' reflective critical thinking (4 items); (iii) interactivity: the extent to which students engage interactively with other students and tutors (4 items); (iv) tutor support: the extent to which tutors support the engagement of students in e-learning (4 items); (v) peer support: the extent to which fellow friends provide sensitive and encouraging support (4 items); and (vi) interpretation: the extent to which students and tutors make good sense of meaning in a congruent and connected manner ( 4 items). ${ }^{17,20}$

COLLES is available in two forms. The first is the "preferred COLLES" that measures students' preferences or expectations for an online learning environment. The preferred COLLES is administered at the beginning of a semester. The second form of the survey is the "actual COLLES" that is administered at the end of the semester to assess students' actual experiences with online learning. Students' perceptions of online learning environment (preferred and actual) can be measured by averaging all items (24 items) to obtain the mean overall COLLES score or by averaging each scale's score. The mean overall preferred and actual COLLES scores can be compared to determine whether the students' expectations for online learning at the beginning of the semester have been met after the completion of the course. Both preferred and actual COLLES are available online and are free to be used by teachers and researchers.

Since the English language is the medium of instruction in UiTM, the survey instrument was not translated into the Malay language. The survey instrument was pilot-tested among a small group of students from the previous batch of students (second-year students, $n=$ 15 and third-year students, $n=15$ ) to assess the comprehensibility of survey items and clarity of response choices. The results from the pilot study were not incorporated into the final analysis of the present study. Findings from the pilot study showed that students took approximately 8-10 min to complete the questionnaire. Additionally, the questionnaire was deemed clear and easy to understand. However, based on the feedback received from the pilot study participants and the consensus among the research team, the Likert-type scale were modified from a five-point scale $(1=$ never, $2=$ seldom, $3=$ sometimes, $4=$ often $/$ frequently and $5=$ almost always) to a four-point scale $(1=$ never, $2=$ seldom, $3=$ sometimes and $4=$ often $/$ frequently) to avoid confusion among participants due to the close meaning of response options 4 and 5 in the original Likert-type scale. The internal consistency reliability of COLLES was good with a Cronbach's $\alpha$ of $>0.80$.

\section{Data collection}

The preferred COLLES was administered at the beginning of the semester (week 1) and the actual COLLES was completed by students after both courses were completed (week 14). In both phases, the questionnaire was distributed by hand by two representative lecturers. All students enrolled in the PP and PC courses were invited to participate in both phases of the study. All students were offered anonymity and confidentiality. Their responses in the survey did not influence their assessment marks or final grades. Completion and return of the questionnaire by the participants implied consent.

\section{Data analysis}

The data was analysed using IBM SPSS ver. 23 . The characteristics of students from the two courses were compared using the chi-square test and independent-samples $t$ test for categorical and continuous data, respectively. The comparison of the preferred and actual COLLES scores (pre- and post-course) in each course utilized the paired-samples $t$ test (intra-group comparison). Students are considered satisfied with the e-learning if there is no significant difference between the preferred and actual COLLES scores. Actual COLLES scores that are significantly lower than the preferred COLLES scores indicate that students' expectations are not being met. 
Inter-group comparison (for gender, entry qualification and course) for both the preferred and actual COLLES scores utilized the independent-samples $t$ test. A $P$ value of $<0.05$ is considered significant.

\section{RESULTS}

Table 1 shows the demographic characteristics of the students included in the study. All PP $(n=196)$ and PC $(n=140)$ students completed the preferred and actual COLLES. There were no dropouts in both phases of the study. Approximately $81 \%$ (273/336) of the students were female. The majority of the students were accepted into the B.Pharm program from matriculation or foundation studies $(64.3 \%, 216 / 336)$. We found no differences in the characteristics of students from the PP and PC courses.

Table 2 shows the mean individual and overall preferred and actual COLLES scores among all students. Overall, students had positive but moderate expectations and satisfaction for e-learning (mean overall preferred COLLES score: $3.33 \pm 0.41$, vs. mean overall actual COLLES score: $3.28 \pm 0.44 ; \mathrm{t}(335)=1.78, P=0.08)$. The average score for each SCLE aspect was $>3$.0. Students had the highest expectation for "relevance" of e-learning (mean preferred relevance: $3.61 \pm 0.42$ ) and the lowest expectation for "peer support" (mean preferred peer support: $3.11 \pm 0.65$ ). Our results showed that students were mostly satisfied with "relevance" of e-learning (mean actual relevance: $3.50 \pm 0.51$ ) and mostly dissatisfied with "peer support" (mean actual peer support: $3.03 \pm$ 0.70). The mean actual COLLES scores for "relevance" and "interpretation" were significantly lower than their respective preferred COLLES score.

Table 3 shows the comparison of preferred and actual COLLES scores (pre- and post-course) among students in each course (PP and PC). The comparison between the preferred and the actual scores for the PP group shows that the students were satisfied with e-learning. This can be seen by the non-significant difference in the mean overall preferred (3.19 \pm 0.33$)$ and actual COLLES scores $(3.20 \pm 0.35)$ among the students: $\mathrm{t}(195)=$ - 0.49, $P=0.62$. The mean scores for "reflection" and "tutor support" significantly increased at the end of the PP course. However, the mean score for "interpretation" significantly decreased. The mean scores for the other aspects of SCLE, i.e., "relevance", "interactivity" and "peer support", were slightly lower for the actual COLLES compared to the preferred COLLES but this difference was not statistically different.

PC students, on the other hand, had lower satisfaction with e-learning, as evidenced by the significantly lower mean overall actual COLLES score $(3.38 \pm 0.53)$ compared to the mean overall preferred COLLES score $(3.54 \pm 0.43): \mathrm{t}(139)=2.83, P<0.01)$. For the PC group, the mean scores for "relevance", "tutor support" and "peer support" were significantly lower at the end of the course. The mean actual COLLES scores for "reflection", "interactivity" and "interpretation" were lower compared to their respective preferred COLLES scores but the differences were not statistically significant.

Table 4 shows the comparison of preferred and actual COLLES scores based on courses (PP vs. PC). The mean overall preferred COLLES score of PC students $(3.54 \pm 0.43)$ was significantly higher than that of $\mathrm{PP}$ students $(3.19 \pm 0.33): \mathrm{t}(247.36)=-8.154, P<0.01)$. The mean overall actual COLLES score of PC students $(3.38 \pm 0.53)$ was also significantly higher than that of PP students $(3.20 \pm 0.35): \mathrm{t}(222.35)=-3.46, P<0.01)$. For the preferred COLLES, the mean score of each of the SCLE aspect was significantly higher in the PC group compared to their PP counterpart. For the actual COLLES, the mean score of each of the SCLE aspect

\begin{tabular}{|c|c|c|c|c|}
\hline \multirow[t]{2}{*}{ Characteristics } & \multicolumn{2}{|c|}{ Student group, $n(\%)$} & \multirow[t]{2}{*}{$P$ value $^{\mathrm{a}}$} & \multirow{2}{*}{$\begin{array}{l}\text { All students } \\
\quad(n=336)\end{array}$} \\
\hline & $\begin{array}{l}\text { Pathology } \\
(n=196)\end{array}$ & $\begin{array}{l}\text { Pharmaceutical care } \\
(n=140)\end{array}$ & & \\
\hline $\mathrm{Age}^{\mathrm{b}}$ & $20.90 \pm 1.28$ & $22.82 \pm 1.37$ & $<0.01^{c}$ & $21.69 \pm 1.62$ \\
\hline $\begin{array}{l}\text { Gender } \\
\text { Male } \\
\text { Female }\end{array}$ & $\begin{array}{c}37(18.9) \\
159(81.1)\end{array}$ & $\begin{array}{l}26(18.6) \\
114(81.4)\end{array}$ & 0.94 & $\begin{array}{c}63(18.8) \\
273(81.2)\end{array}$ \\
\hline $\begin{array}{c}\text { Previous education } \\
\text { Matriculation/Foundation } \\
\text { Diploma in Pharmacy or other related } \\
\text { diplomas }\end{array}$ & $\begin{array}{l}126(64.3) \\
70(35.7)\end{array}$ & $\begin{array}{l}90(64.3) \\
50(35.7)\end{array}$ & 1.00 & $\begin{array}{l}216(64.3) \\
120(35.7)\end{array}$ \\
\hline
\end{tabular}




\begin{tabular}{|c|c|c|c|}
\hline \multicolumn{2}{|c|}{ Table 2: Mean overall preferred and actual COLLES scores of students $(\boldsymbol{n}=336)}$. \\
\hline Aspect of SCLE & $\begin{array}{c}\text { Preferred COLLES } \\
\text { score }^{\mathbf{a}}\end{array}$ & $\begin{array}{c}\text { Actual COLLES } \\
\text { score }^{\mathbf{a}}\end{array}$ & $\boldsymbol{P}_{\text {value }}$ \\
\hline Relevance & $3.61(0.42)$ & $3.50(0.51)$ & $<0.01$ \\
\hline Reflection & $3.26(0.56)$ & $3.29(0.54)$ & 0.59 \\
\hline Interactivity & $3.15(0.62)$ & $3.09(0.63)$ & 0.17 \\
\hline Interpretation & $3.41(0.52)$ & $3.29(0.58)$ & $<0.01$ \\
\hline Tutor Support & $3.45(0.55)$ & $3.47(0.58)$ & 0.72 \\
\hline Peer Support & $3.11(0.65)$ & $3.03(0.70)$ & 0.10 \\
\hline Overall & $3.33(0.41)$ & $3.28(0.44)$ & 0.08 \\
\hline
\end{tabular}

${ }^{\text {a }}$ Mean (standard deviation)

b Paired-samples $t$ test used

\begin{tabular}{|c|c|c|c|c|c|c|}
\hline \multirow{2}{*}{$\begin{array}{l}\text { Aspect of } \\
\text { SCLE }\end{array}$} & \multicolumn{3}{|c|}{ PP } & \multicolumn{3}{|c|}{ PC } \\
\hline & $\begin{array}{c}\text { Preferred } \\
\text { COLLES } \\
\text { score }^{\mathrm{a}}\end{array}$ & $\begin{array}{l}\text { Actual } \\
\text { COLLES } \\
\text { score }^{\mathrm{a}}\end{array}$ & $P$ value $^{\mathrm{b}}$ & $\begin{array}{c}\text { Preferred } \\
\text { COLLES } \\
\text { score }^{\mathrm{a}}\end{array}$ & $\begin{array}{l}\text { Actual } \\
\text { COLLES } \\
\text { score }^{\mathrm{a}}\end{array}$ & $P$ value $^{\mathrm{b}}$ \\
\hline Relevance & $3.51(0.42)$ & $3.48(0.41)$ & 0.61 & $3.75(0.39)$ & $3.53(0.63)$ & $<0.01$ \\
\hline Reflection & $3.07(0.47)$ & $3.18(0.45)$ & 0.02 & $3.54(0.56)$ & $3.43(0.62)$ & 0.14 \\
\hline Interactivity & $2.99(0.55)$ & $2.97(0.57)$ & 0.84 & $3.38(0.64)$ & $3.25(0.68)$ & 0.08 \\
\hline Interpretation & $3.28(0.48)$ & $3.17(0.53)$ & 0.04 & $3.58(0.54)$ & $3.45(0.61)$ & 0.07 \\
\hline Tutor Support & $3.30(0.53)$ & $3.45(0.51)$ & $<0.01$ & $3.67(0.50)$ & $3.49(0.66)$ & 0.01 \\
\hline Peer Support & $2.96(0.59)$ & $2.95(0.62)$ & 0.81 & $3.32(0.68)$ & $3.14(0.78)$ & 0.04 \\
\hline Overall & $3.19(0.33)$ & $3.20(0.35)$ & 0.62 & $3.54(0.43)$ & $3.38(0.53)$ & $<0.01$ \\
\hline
\end{tabular}

PP: Principle of pathology, PC: Pharmaceutical care

a Mean (standard deviation)

b Paired-samples $t$ test used

\section{Table 4: Comparison of preferred and actual COLLES scores based on course.}

\begin{tabular}{|c|c|c|c|c|c|c|}
\hline \multirow{2}{*}{$\begin{array}{l}\text { Aspect of } \\
\text { SCLE }\end{array}$} & \multicolumn{3}{|c|}{ Preferred COLLES score ${ }^{a}$} & \multicolumn{3}{|c|}{ Actual COLLES score ${ }^{a}$} \\
\hline & $\begin{array}{c}\text { PP } \\
(n=196)\end{array}$ & $\begin{array}{c}\text { PC } \\
(n=140)\end{array}$ & $P$ value $^{\mathrm{b}}$ & $\begin{array}{c}\text { PP } \\
(n=196)\end{array}$ & $\begin{array}{c}\text { PC } \\
(n=140)\end{array}$ & $P$ value $^{\mathrm{b}}$ \\
\hline Relevance & $3.51(0.42)$ & $3.75(0.39)$ & $<0.01$ & $3.48(0.41)$ & $3.52(0.63)$ & 0.51 \\
\hline Reflection & $3.07(0.47)$ & $3.54(0.56)$ & $<0.01$ & $3.18(0.45)$ & $3.43(0.62)$ & $<0.01$ \\
\hline Interactivity & $2.99(0.55)$ & $3.38(0.64)$ & $<0.01$ & $2.97(0.57)$ & $3.25(0.68)$ & $<0.01$ \\
\hline Interpretation & $3.29(0.48)$ & $3.58(0.54)$ & $<0.01$ & $3.17(0.53)$ & $3.45(0.61)$ & $<0.01$ \\
\hline Tutor Support & $3.30(0.53)$ & $3.67(0.50)$ & $<0.01$ & $3.45(0.51)$ & $3.49(0.66)$ & 0.59 \\
\hline Peer Support & $2.96(0.59)$ & $3.32(0.68)$ & $<0.01$ & $2.95(0.62)$ & $3.14(0.78)$ & 0.02 \\
\hline Overall & $3.19(0.33)$ & $3.54(0.43)$ & $<0.01$ & $3.20(0.35)$ & $3.38(0.53)$ & $<0.01$ \\
\hline
\end{tabular}

PP: Principle of pathology, PC: Pharmaceutical care

${ }^{a}$ Mean (standard deviation)

${ }^{\mathrm{b}}$ Independent-samples $t$ test used

was generally higher in the PC group compared to the PP group. PC students had significantly higher mean actual COLLES scores for "reflection", "interactivity", "interpretation" and "peer support" compared to the PP students.

\section{DISCUSSION}

Our findings show that both PP and PC students expected the environment of their e-learning to be SCLE. This means that they preferred their e-learning experience to be relevant, able to stimulate critical 
thinking and allow interactions with peers and tutors. In addition, the students expected to receive encouragement and support from both tutors and peers. Among all aspects of the SCLE, PP and PC students expected the most for e-learning to be relevant and they did not put high expectations for peer support. In Thailand, Sthapornnanon and colleagues also reported that their third-year students who enrolled in Pharmacy Professional Practice in Pharmaceutical Marketing and Business course also preferred their e-learning to be SCLE. ${ }^{21}$ Consistent with our findings, the Thai students also rated relevance as the most preferred aspect of SCLE for e-learning.

In general, students from both PP and PC courses were satisfied with e-learning. The actual COLLES score shows that students were satisfied the most with the relevance of the e-learning that they received. The PC students, however, reported higher satisfaction for e-learning than the PP students, as evidenced by the significantly higher mean overall actual COLLES score in the PC group. One possible explanation is that the PC students were older than the PP students and older students have been reported to have higher motivation and more serious attitude towards education. ${ }^{22}$ Two aspects of the SCLE that were mostly dissatisfied by the students are related to "interactivity" and "peer support". These findings are comparable to those reported by Sthapornnanon and colleagues. ${ }^{21}$

Our study did not capture the frequency of students' participation or how much they provided comments or feedback to their peers. However, the low level of students' satisfaction with the level of interactions and peer support that they received in their e-learning may suggests that many students did not actively participate in e-learning activities that require interactions among students (e.g., sharing ideas, recommending solutions, asking questions, etc.). One possible explanation is that our students may not be ready to interact with their peers to obtain knowledge. They may still expect to receive knowledge from tutors as in the traditional teaching methods. ${ }^{21}$ In addition, students may not be comfortable in giving comments or opinions to peers as these are normally the roles of tutors. The high number of students in each class (PP, $n=196$; and PC, $n=140$ ) may also contributed to the low level of interactions among students and caused the provision of peer support to be more difficult. Therefore, it is recommended to break a large class into smaller interactive activities to enhance students' participation and involvement in e-learning. Smaller groups also provide a more comfortable environment for them to share information and provide feedback to others. In addition, tutors should emphasize the importance of students' participation in e-learning activities and highlight their responsibilities to ensure that they benefit from e-learning. ${ }^{23}$

Our findings show that PP students were generally satisfied with their e-learning whereas for the PC students, their overall expectations for e-learning were not fulfilled. Moreover, the PC students were noted to be dissatisfied with the "relevance", "tutor support" and "peer support" of the PC course. Of note, the PC course that is offered in the third year is a more "applied" and "complex" compared to the PP course. Being a more complex course, it demands higher thinking skills among students and therefore they may desire more attention and support from their tutors and friends. The reduced level of "relevance" that the PC students experienced at the end of the course indicated that they were not sufficiently challenged. Our findings suggest that there is a need to consider the complexity of a particular course in e-learning development. Learning content and activities that are more challenging can be tailored to students in higher classes, so that they are adequately challenged. The high expectations expressed by the PC group were not surprising. The literature suggests that students normally put high expectations for new innovation in teaching and they hope to get the most from this form of learning. ${ }^{6,21}$ However, it is challenging for these high expectations to be fully met. Previous studies have reported actual COLLES scores that are lower than the preferred COLLES scores among students. ${ }^{17,21,24}$ These results, however, reflected students' acceptance and interests for e-learning in education. It is worth noting that although the actual COLLES scores of PC students in all aspects of SCLE were lower than the preferred COLLES scores (three of which were significant), the scores did not fall below the "desirable" range (3.0 - 4.0 [sometimes - often/frequently]) (Table 3). This indicates that even though the PC students' expectations were not met, they still perceived their e-learning as SCLE to some extent. In addition, the differences in the two values (preferred and actual COLLES scores) were not wide, suggesting that the students' high expectations were actually close to being realized in practice. The tutors and e-learning developers should therefore aim to narrow this gap by reshaping e-learning materials and processes to ensure that the satisfaction among students is optimum. ${ }^{25}$ This is important since students' satisfaction for e-learning corresponds to the success of the method and ensures continuous participation of students in this form of learning. ${ }^{26,27}$

The strengths of our study included the high participation of students in both phases (100\% response rate) and the use of COLLES questionnaires in our survey. 
Limitations of the present study included the inclusion of only two groups of students from only one university. The study participants therefore may not represent pharmacy students as a whole. In addition, we compared two student groups enrolling in two different courses that have different contents and levels of complexity. Although the e-learning components of the two courses were developed, coordinated, maintained and delivered by the same group of tutors, the differences may affect students' perceptions about SCLE of the e-learning components to some extent. Moreover, although it appears that e-learning offered to the students is viable, this conclusion is made solely based on students' perceptions. While students' expectations and perceptions are crucial, the design of good e-learning materials should include other evaluation metrics. An assessment of students' knowledge gained after engaging in our e-learning materials can provide further evidence on the effectiveness of this form of learning. Future study should aim to identify barriers to students' participations in collaborative learning and to strategize ways to improve it.

\section{CONCLUSION}

Our findings show that students' regarded their e-learning as SCLE. The students from both courses in general had positive but moderate expectations and experience in e-learning. Pharmacy educators should take advantage by offering e-learning in their teachings due to its general acceptance by students. Even so, the expectations of the third-year PC students were harder to fulfil. There is a need to innovate and tailor e-learning content for the senior students so that they can receive adequate support from their tutors and friends and at the same time are adequately challenged in learning. We also noted a pressing need to improve students' participation in interactive and collaborative learning.

\section{ACKNOWLEDGEMENT}

This work was supported by Academic and Research Assimilation Grants: 600-IRMI/DANA 5/3/ARAS (0022/2016). The authors would like to express their gratitude to Ministry of Higher Education and Universiti Teknologi MARA (UiTM), Malaysia for the financial support for this research. The funders had no role in study design, data collection and analysis, decision to publish, or preparation of the manuscript.

\section{CONFLICT OF INTEREST}

The authors declare no conflict of interest.

\section{ABBREVIATIONS}

COLLES: Constructivist Online Learning Environment Survey; PC: Pharmaceutical Care; PP: Principle of Pathology; SCLE: Social Constructivist Learning Environment; SCT: Social Constructivism Theory.

\section{REFERENCES}

1. Ruiz JG, Mintzer MJ, Leipzig RM. The impact of e-learning in medical education. Academic Medicine. 2006;81(3):207-12.

2. Legris MÉ, Séguin NC, Desforges K, Sauvé P, Lord A, Bell R, et al. Pharmacist web-based training program on medication use in chronic kidney disease patients: Impact on knowledge, skills, and satisfaction. Journal of Continuing Education in the Health Professions. 2011;31(3):140-50.

3. Erickson SR, Chang A, Johnson CE, Gruppen LD. Lecture versus Web tutorial for pharmacy students' learning of MDI technique. Annals of Pharmacotherapy. 2003;37(4):500-5.

4. Flowers SK, Vanderbush RE, Hastings JK, West D. Web-based multimedia vignettes in advanced community pharmacy practice experiences. American Journal of Pharmaceutical Education. 2010;74(3):39.

5. Blouin RA, Riffee WH, Robinson ET, Beck DE, Green C, Joyner PU, et al. Roles of innovation in education delivery. American Journal of Pharmaceutical Education. 2009;73:54.

6. Carbonaro M, King S, Taylor E, Satzinger F, Snart F, Drummond J. Integration of e-learning technologies in an interprofessional health science course. Medical Teacher. 2008;30(1):25-33.

7. Brandys J, Polak S, Mendyk A, Polak M. An e-learning system for pharmacist continuing education in Poland. Pharmacy Education. 2006;6(1).

8. Cain J, Fox BI. Web 2.0 and pharmacy education. American Journal of Pharmaceutical Education. 2009;73(7):120.

9. Wahab MSA, Sakthong P, Winit-Watjana W. Pharmacy students' attitudes and perceptions about complementary and alternative medicine: A systematic review. Thai Journal of Pharmaceutical Sciences. 2016;40(2).

10. Zakariah Z, Alias N, Aziz MNA, Ismail NZ. E-Learning Awareness in a Higher Learning Institution in Malaysia. Procedia-Social and Behavioral Sciences. 2012;67:621-5.

11. Hall DL, Corman SL, Drab SR, Smith RB, Meyer SM. Application of a technology-based instructional resource in diabetes education at multiple schools of pharmacy: Evaluation of student learning and satisfaction. Currents in Pharmacy Teaching and Learning. 2010;2(2):108-13.

12. Elliott RA, McDowell J, Marriott JL, Calandra A, Duncan G. A pharmacy preregistration course using online teaching and learning methods. American Journal of Pharmaceutical Education. 2009;73(5):77.

13. Battaglia JN, Kieser MA, Bruskiewitz RH, Pitterle ME, Thorpe JM. An online virtual-patient program to teach pharmacists and pharmacy students how to provide diabetes-specific medication therapy management. American Journal of Pharmaceutical Education. 2012;76(7):131.

14. Walters C, Raymont A, Galea S, Wheeler A. Evaluation of online training for the provision of opioid substitution treatment by community pharmacists in New Zealand. Drug and Alcohol Review. 2012;31(7):903-10.

15. Huang HM. Toward constructivism for adult learners in online learning environments. British Journal of Educational Technology. 2002;33(1):27-37.

16. Wink J, Putney LG. A vision of Vygotsky. Boston: Allyn and Bacon. 2002.

17. Herrmann A. KMM, ed. Assessing the efficacy of online teaching with the Constructivist Online Learning Environment Survey. $9^{\text {th }}$ Annual Teaching Learning Forum; Perth, Australia. 2000.

18. Ramly S, Yunos SY, Ahmad TSAS, Jamil NI. Investigating the Usefulness of Blended Learning: A Case of UiTM Negeri Sembilan. Envisioning the Future of Online Learning: Springer. 2016;305-16.

19. Lecturers' experiences in implementing blended learning using i-Learn. International Conference on Science and Social Research (CSSR); Kuala Lumpur, Malaysia. IEEE. 2010.

20. Reynolds RA. Handbook of research on electronic surveys and measurements. Hershey, PA: IGI Global. 2006. 
Sthapornnanon N, Sakulbumrungsil R, Theeraroungchaisri A Watcharadamrongkun S. Social constructivist learning environment in an online professional practice course. American Journal of Pharmaceutical Education. 2009;73:10.

Fredericksen E, Pickett A, Shea P, Pelz W, Swan K. Student satisfaction and perceived learning with on-line courses: Principles and examples from the SUNY learning network. JALN. 2000;4(2):7-41

23. DeVega CA, McAnally-Salas L, Lavigne G. Attitudes and Perceptions of Students in a Systems Engineering E-Learning Course. Acta Didactica Napocensia. 2009;2(2):95-110.
24. Analysing the efficacy of blended learning using Technology Enhanced Learning (TEL) and m-learning delivery technologies. 23 ${ }^{\text {rd }}$ Australasian Society for Computers in Learning in Tertiary Education Conference; Sydney, Australia. 2006.

25. Sachs D, Hale N. Pace university's focus on student satisfaction with student services in online education. JALN. 2003;7(2):36-42.

26. Levy Y. A study of learners' perceived value and satisfaction for implied effectiveness of online learning systems. Florida International University. 2003.

27. Levy Y. Comparing dropouts and persistence in e-learning courses. Computers and Education. 2007;48(2):185-204.

\section{SUMMARY}

- Overall, students had positive but moderate expectations and satisfaction for e-learning.

- This means that they preferred their e-learning experience to be relevant, able to stimulate critical thinking and allow interactions with peers and tutors.

- The comparison between the preferred and the actual Constructivist Online Learning Environment Survey (COLLES) scores for the Principle of Pathology (PP) group shows that the students were satisfied with e-learning.

- The Pharmaceutical Care (PC) students had lower satisfaction with e-learning, as evidenced by the significantly lower mean overall actual COLLES score compared to the mean overall preferred COLLES score.

- This is due to the fact that PC course is a more complex course that demands higher thinking skills among students and therefore students may desire more attention and support from their tutors and friends.

- There is a need to innovate and tailor e-learning content for the senior students so that they can receive adequate support from their tutors and friends and at the same time are adequately challenged in learning.

PICTORIAL ABSTRACT

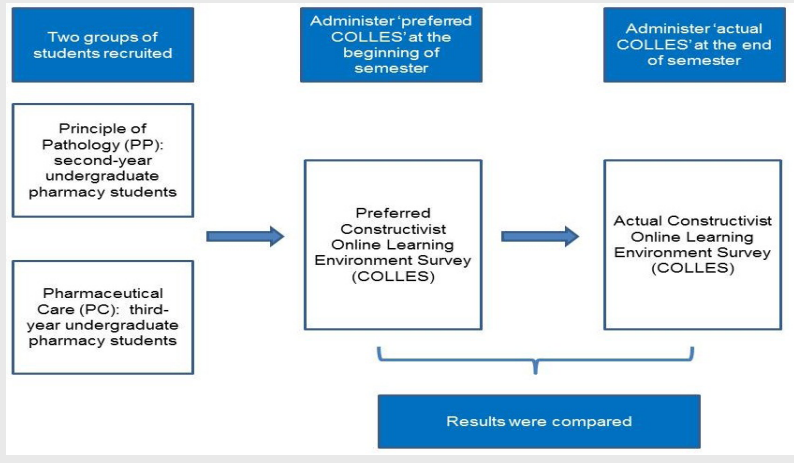

\section{About Authors}

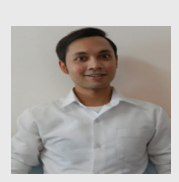

Dr. Mohd Shahezwan Abd Wahab graduated from Universiti Teknologi MARA (UiTM) with Bachelor of Pharmacy (Honours) in 2006. He later obtained Master of Clinical Pharmacy from the School of Pharmacy and Medical Sciences, University of South Australia (UNISA), Australia in 2010. In 2018, he received his $\mathrm{Ph.D}$ in Pharmaceutical Care from the Faculty of Pharmaceutical Sciences, Chulalongkorn University, Thailand. Dr. Mohd Shahezwan Abd Wahab's research interests include pharmaceutical care, pharmacy practice, herbal and dietary supplements, and pharmacy education. Currently Dr. Mohd Shahezwan Abd Wahab is the Deputy Dean for Students' Affairs at UiTM.

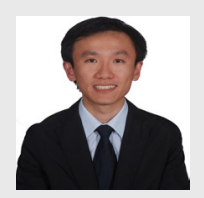

Assoc. Prof. Dr. Long Chiau Ming completed his Bachelor of Pharmacy (Honours) and Master of Clinical Pharmacy at Universiti Sains Malaysia (USM) in 2005 and 2009, respectively. He obtained his Ph.D from the Department of Pharmacy and Pharmacology, University of Bath, England in 2014. To date, he has more than ten years of academic, research and industrial experiences. He publishes widely in the field of clinical studies and health services research. Assoc. Prof. Dr. Long Chiau Ming is also the Associate Editor of BMC Health Services Research, Executive Committee Malaysian Society of Pharmaceutical Technology (MSPT). Currently, he holds the position of Associate Professor at PAP Rashidah Sa'adatul Bolkiah Institute of Health Sciences, Universiti Brunei Darussalam (UBD). His research group is active in research related to public health, clinical pharmacy and data science.

Cite this article: Azhari FA, Jasmi NN, Wahab MSA, Jofrry SM, Lee KS, Ming LC. Students' Perceptions about Social Constructivist Learning Environment in E-learning. Indian $\mathrm{J}$ of Pharmaceutical Education and Research. 2020;54(2):271-8. 